\title{
RADIO ASTRONOMY
}




\section{INTERNATIONAL ASTRONOMIGAL UNION SYMPOSIUM No. 4}

HELD AT THE JODRELL BANK EXPERIMENTAL STATION

NEAR MANGHESTER, AUGUST I 955

\section{RADIO ASTRONOMY}

EDITED BY

H. G. VAN DE HULST

Leiden Observatory

PRINTED WITH

FINANCIAL ASSISTANCE

$F R O M$ U.N.E.S.G.O.

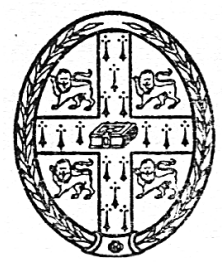

CAMBRIDGE

AT THE UNIVERSITY PRESS

I 957 
PUBLISHED BY

THE SYNDICS OF THE CAMBRIDGE UNIVERSITY PRESS

Bentley House, 200 Euston Road, London, N.W. I American Branch: 32 East 57th Street, New York 22, N.Y.

Printed in Great Britain at the University Press, Cambridge (Brooke Crutchley, University Printer) 


\section{GONTENTS}

Preface

page $\mathbf{v}$

PAR T I

\section{SPEGTRAL LINE INVESTIGATIONS}

PAPER

1. H. C. VAN DE Hulst: Studies of the $21-\mathrm{cm}$. line and their interpretation (Introductory Lecture)

2. M. Stahr Carpenter: $21-\mathrm{cm}$. observations in Sydney

3. F. K. Edmondson: Deviations from circular motion and the importance of southern hemisphere $2 \mathrm{I}-\mathrm{cm}$. observations

4. G. Westerhout: Progress report on $2 \mathrm{I}-\mathrm{cm}$. research by the Netherlands Foundation for Radio Astronomy and the Leiden Observatory

5. G. Westerhout: A $2 \mathrm{I}-\mathrm{cm}$. line survey of the outer parts of the Galaxy

6. M. SснміDт: The distribution of atomic hydrogen in the inner parts of the Galaxy

7. B. J. Bok: Progress report on the project in Radio Astronomy at the G. R. Agassiz station of Harvard Observatory

8. T. A. Matthews: Report on $2 \mathrm{I}-\mathrm{cm}$. observations between $l=60^{\circ}$ and $l=135^{\circ}$

9. T. K. Menon: A $21-\mathrm{cm}$. study of the Orion region

10. R. S. LAWRENCE: Radio observations of interstellar neutral hydrogen clouds

11. H. E. TATEL: 2 I -cm. meridian plane surveys

12. R. D. Davies and D. R. W. Williams: The measurement of the distance of the radio sources

13. J. P. HAGEN, A. E. LiLLEY and E. F. MGCLAIN: 2 I-cm. absorption effects

14. F. K. EDmondson: Comments on McClain's observations of I.A.U. I $7 \mathrm{~S}_{2} \mathrm{~A}$

15. G. G. Getmanzev, K. S. Stankevitgh and V.S. Troitzky: Detection of the spectral line of deuterium from the centre of the Galaxy on the wave-length of $9_{1} \cdot 6 \mathrm{~cm}$.

16. C. H. Townes: Microwave and radio-frequency resonance lines of interest to radio astronomy 


\section{POINT SOURGES: INDIVIDUAL STUDY AND PHYSICAL THEORY}

17. R. Minkowski: Optical investigations of radio sources (Introductory Lecture)

18. J. L. PAwsey: Current progress in development and results obtained with the 'Mills Cross' at the Radiophysics Laboratory

19. J. D. Kraus, H. G. Ko, R. T. Nash and D. V. Stoutenburg: Recent results in radio astronomy at the Ohio State University

20. J. P. HAGEN: Spectra of some radio sources

21. R. J. LAMDEN and A. C. B. Love L L: The low-frequency spectrum of Cygnus A and Cassiopeia A

22. H. W. WeLls: Preliminary observations of point sources at 12.5 and $15.5 \mathrm{Mc} . / \mathrm{s}$.

23. B. F. BURKE and K. L. FRANKLIN : Observations of discrete sources with the $22 \mathrm{Mc}$./s. Mills Cross

24. Gh. L. Seeger: The $400 \mathrm{Mc}$./s. flux from Cassiopeia A

25. V. A. Razin and V. M. Pletghiov: Intensities of the discrete sources in Cassiopeia, Cygnus and Taurus at $\lambda 3.2 \mathrm{~cm}$.

26. CH. L. SEEGER: The radio frequency spectrum of Cassiopeia A: a Symposium summary

27. R. G. Jennison: Intensity distribution across the Cygnus and Cassiopeia sources

28. H. P. PALMER: The angular diameter of discrete radio sources

29. F. G. Smith, P. A. O'Brien and J. E. Baldwin: The discrete source of radio waves at the galactic centre

30. G. De Vaugouleurs and K. V. Sheridan: Radio and optical intensity distributions in the Centaurus source $\left(\mathrm{NGC}_{5}{ }_{2} 28\right)$

31. J. G. Bolton and O. B. SleE: Apparent intensity variations of the radio source Hydra $A$

32. J. L. GREENSTEIN: Theoretical problems of discrete radio sources

33. F. T. HADDOGK: Hydrogen emission nebulae as radio sources

34. J. H. OORt and T. WALraven: Polarization and the radiating mechanism of the Crab nebula

35. I. S. Shklovsky: Optical emission from the Crab nebula in the continuous spectrum

36. I. S. Shklovsky: On the nature of the emission from the Galaxy NGG 4486 


\section{GALACTIC STRUGTURE AND STATISTICAL STUDIES OF POINT SOURGES}

37. R. HANBURY Brown: Galactic radio emission and the distribution of discrete sources (Introductory Lecture)

38. J. R. Shakeshaft: The Cambridge survey of radio sources 218

39. M. RYLE: The spatial distribution of radio stars

40. J. L. PAWsey: Preliminary statistics of discrete sources obtained with the 'Mills Cross'

41. J. E. BALDWIN: The spherical component of the galactic radio emission

42. A. UNSÖLD: Radio astronomy and the origin of cosmic rays

43. I. S. ShK Lovsky: Some problems of metagalactic radio-emission

44. G. DE VAuGouleurs: Comparison between radio and optical surface brightness distributions in the Magellanic Clouds

\section{PART IV}

\section{THE QUIET SUN}

45. C. W. Allen: The quiet and active sun (Introductory Lecture)

46. J. P. HAGEN: The structure of the solar chromosphere from centimetre-wave radio observations

47. G. H. Mayer, R. M. Sloanaker and J. P. Hagen: Observation of the solar eclipse of 30 June 1954 at $9.4 \mathrm{~cm}$. wave-length

48. F. T. HADDOCK: The radial brightness distribution of the sun at $9.4 \mathrm{~cm}$.

49. Righard N. Thomas and R. G. Athay: On the uniformity of the lower chromosphere

50. J. L. Pawsey: Observations of brightness over the disk of the quiet sun at frequencies of 85,500 and $1400 \mathrm{Mc}$./s.

51. S. F. SMERD and J. P. WILD: Interpretation of solar radiofrequency disk brightness distributions derived from observations with aerials extended in one dimension

52. J. FIROR: Brightness distribution of the sun at $\mathrm{I} \cdot 45$ metres

53. A. Hewish: Radio observations of the solar corona at sunspot minimum 
54. J. Tuominen: The ellipticity of the corona at $80 \mathrm{Mc} . / \mathrm{s}$. during sunspot minimum 1954

55. M. LAFFINEUR: Radio observations of the eclipse of 30 June 1954

56. T. Hatanaka: Radio observation of the partial solar eclipse, 20 June I955

57. B. M. Тснікнатянev: A survey of Soviet observations of the radio emission from the sun during solar eclipses

58. V. V. Viткеviтch: Results of observations of the scattering of radio waves by the electronic inhomogeneities of the solar corona

PART V

\section{THE ACTIVE SUN}

59. J. P. WILD: Spectral observations of solar activity at metre wavelengths

60. H. W. Dodson: Relation between optical solar features and solar radio emission

61. P. Simon: Sunspots: radio, optical and geomagnetic features

62. W. O. R о B E R Ts: Optical evidences of radiational and corpuscular emission from active solar regions

336

63. M. WALDMEIER: The enhanced radiation from sunspot-regions

64. D. H. MENZEL and M. KROOK: On the origin of solar radio noise

65. K. O. KIEPENHEUER: On the mechanism of solar outbursts

66. L. BIERMANN and R. Lüst : Remarks on the energy of the nonthermal radio-frequency emission

67. A. SGHLÜteR: Solar radio emission and the acceleration of magnetic-storm particles

68. T. Hatanaka: Polarization of solar radio bursts

69. V. V. Viткеviтgh: Disturbed radio emission from the sun as a sum of small monochromatic peaks

70. C. DE JAGER and F. VAN 'T VEER: Some properties of solar radio-transients on fast $200 \mathrm{Mc}$./s. records

71. A. D. Fokker: A peculiar type of scintillation of solar radio radiation 


\section{METEORS AND PLANETS}

72. F. L. Whipple: Some problems of meteor astronomy (Introductory Lecture)

73. J. G. Davies: Orbits of sporadic meteors

74. I. C. Browne, K. Bullough, S. Evans and T. R. Kaiser: The distribution of meteor masses

75. B. F. BURKE and K. L. FRANKLIN: Jupiter as a radio source

76. C. A. ShaIn: Location on Jupiter of a source of radio noise

77. F. Link: Possible proofs of the lunar atmosphere

78. B. Elsmore: The lunar occultation of a radio star and the derivation of an upper limit for the density of the lunar atmosphere

79. V. S. Troitzky and S. E. Khaikin: Radio emission from the moon and the nature of its surface

80. I. C. BROWNE and J. V. EVANS: The moon as a scatterer of radio waves 